Ryan David (Orcid ID: 0000-0002-1264-7165)

\title{
Inhibition of interleukin 6 signalling and renal function: a
} Mendelian randomization study

Running head title: Interleukin-6 signalling and renal function

David K Ryan, MBChB, Academic Foundation Doctor ${ }^{1,2}$

Ville Karhunen, PhD, Postdoctoral Researcher ${ }^{3}$

Drew J Walker, MBBS MPharm, Clinical Fellow ${ }^{1,2}$

Dipender Gill, BMBCh PhD, Clinician Scientist ${ }^{1-4}$

\section{Author Affiliations}

1. Clinical Pharmacology Group, Pharmacy and Medicines Directorate, St George's University Hospitals NHS Foundation Trust, London, UK.

2. Clinical Pharmacology and Therapeutics Section, Institute of Medical and Biomedical Education and Institute for Infection and Immunity, St George's, University of London, London, UK.

3. Department of Epidemiology and Biostatistics, School of Public Health, Imperial College London, London, UK.

4. Novo Nordisk Research Centre Oxford, Old Road Campus, Oxford, UK.

Corresponding author contact information: David K Ryan, Clinical Pharmacology Group, Institute of Medical and Biomedical Education and Institute for Infection and Immunity, St George's, University of London, Cranmer Terrace, SW17 0RE, London, UK.

\section{davidkdryan@gmail.com}

This article has been accepted for publication and undergone full peer review but has not been through the copyediting, typesetting, pagination and proofreading process which may lead to differences between this version and the Version of Record. Please cite this article as doi: 10.1111/bcp. 14725 
Conflict of interest statement: Dipender Gill is employed part-time by Novo Nordisk. The remaining authors have no conflicts of interest to declare.

Keywords: Interleukin-6, chronic kidney disease, cardiovascular disease, Mendelian randomisation study.

\section{Word count:}

Abstract: 150

Main text: 1983

\section{Acknowledgements}

We would like to acknowledge the UK Biobank and the Chronic Kidney Disease Genetics (CKDGen) Consortium for releasing GWAS summary data. We would also like to acknowledge the work of Georgakis et al who identified and published the instrumental variables for interleukin-6 signalling employed in sensitivity analysis.

Principal Investigator: David K Ryan. No human participants participated in the study directly. This study involved secondary analysis of publicly available genome-wide association studies.

\section{Funding information}

DKR was supported by a St George's University academic training grant. VK and DG are supported by the British Heart Foundation Research Centre of Excellence (RE/18/4/34215) at Imperial College London.

Data availability Statement: All data used in this study are publicly available. The statistical code used in this work is available from the corresponding author upon reasonable request.

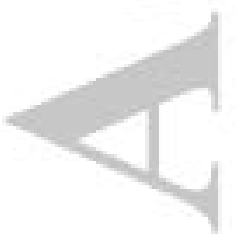




\section{What is already known?}

- Inhibition of interleukin 6 (IL-6) signalling has shown promising potential for lowering cardiovascular risk.

- Patients with chronic kidney disease (CKD) have a high burden of cardiovascular disease, likely mediated in part due to a low-grade and persistent inflammatory state.

- There is growing interest in using IL-6 inhibitors to reduce cardiovascular risk in patients with CKD.

\section{What this study adds}

- This Mendelian randomization study did not identify evidence to support that genetically proxied inhibition of IL-6 signalling is associated with changes in renal function.

- Adverse effects on renal function directly related to IL-6 inhibition are unlikely to limit this therapeutic strategy for reducing cardiovascular disease risk in patients with CKD.

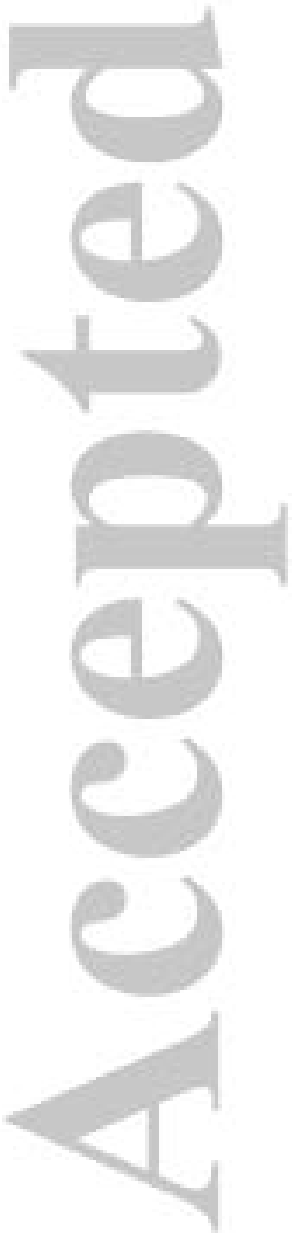




\section{Abstract}

Inhibition of interleukin 6 (IL-6) signalling has been proposed as a potential cardioprotective strategy for patients with chronic kidney disease (CKD), but the direct effects of IL-6 inhibition on renal function are not known. A Mendelian randomization (MR) study was performed to investigate the association of genetically proxied inhibition of IL-6 signalling with estimated glomerular filtration rate (eGFR), CKD and blood urea nitrogen (BUN). Inverse-variance weighted MR was used as the main analysis, with sensitivity analyses performed using simple median, weighted median and MR-Egger methods. There was no evidence for an association of genetically proxied inhibition of IL-6 signalling (scaled per standard deviation unit decrease in C-reactive protein) with log eGFR $(0.001,95 \%$ confidence interval -0.004-0.007), BUN (0.009, 95\% confidence interval -0.003-0.021) and CKD (odds ratio $0.948,95 \%$ confidence interval $0.822-1.094$ ). These findings do not raise concerns for IL-6 signalling having large adverse effects on renal function.

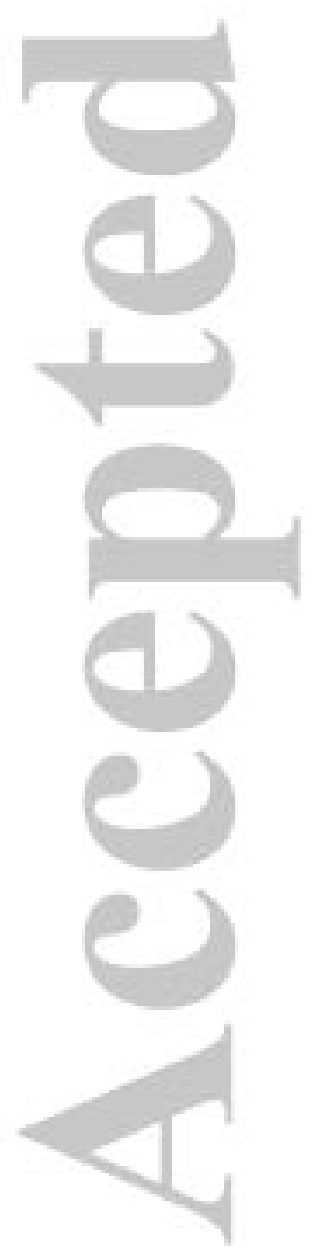




\section{Introduction}

Cardiovascular disease (CVD) accounts for half of all deaths in end-stage renal failure and the burden of CVD in chronic kidney disease (CKD) is not fully explained by traditional risk factors. ${ }^{1}$ This suggests that alternative pathways may be implicated in the disproportionately high CVD risk in patients with declining renal function. ${ }^{2}$ CKD is recognised as a low-grade but persistent inflammatory state, with raised levels of inflammatory biomarkers such as interleukin-1 $\beta$ (IL-1 $\beta$ ) interleukin-6 (IL-6) and C-reactive protein (CRP). ${ }^{3}$ Inflammation plays a critical role in atherosclerosis and it is possible that the inflammatory milieu of CKD contributes to the excessive risk of CVD in CKD. ${ }^{4,5}$ Inflammatory markers including highsensitive CRP and IL-6 are predictive of cardiovascular events and IL-6 levels are independent predictors of CVD and mortality in patients with CKD. ${ }^{6,7}$ Pharmacological inhibition of IL- $1 \beta$ by the monoclonal antibody canakinumab has reduced rates of major cardiovascular events in patients with CKD who had a previous myocardial infarction. ${ }^{8}$ Further analysis of canakinumab showed that the cardioprotective effect was dependent on inhibition of IL-6 levels in a general population. ${ }^{9}$ There are now ongoing plans to commence trials of the IL-6 signalling inhibitor, ziltivekimab, for reduction of CVD in patients with CKD. ${ }^{10}$ However, it has not been established whether direct IL- 6 signalling inhibition has an impact on renal function.

Mendelian randomization (MR) employs genetic polymorphisms as instrumental variables to study the effect of an exposure on an outcome. ${ }^{11} \mathrm{MR}$ is less susceptible to confounding due to the random allocation of genetic variants and balancing of environmental factors at conception. For a valid MR study, the following assumptions must hold: the genetic proxy must be associated with the exposure, the genetic variant only affects the outcome through the exposure of interest with no horizontal pleiotropic effect, the genetic variant is not associated with any known confounder affecting the exposure and the outcome. ${ }^{11} \mathrm{~A}$ valid MR study is analogous to an endogenous randomised controlled trial based on the randomisation of genetic variants at conception. Applied to drug development, MR provides an in-silico platform to predict adverse drug consequences, explore drug repurposing and determine whether new therapeutic strategies are suitable to be trialled among vulnerable populations, such as patients with CKD. ${ }^{12}$ Considering the growing interest of IL-6 inhibition in patients with CKD, the aim of the present study was to investigate the effect of inhibition of IL-6 signalling on renal function by MR methods. 


\section{Methods}

A two-sample MR study was conducted to investigate the association of genetically proxied inhibition of IL-6 signalling with different measures of renal function: estimated glomerular filtration rate (eGFR), CKD and blood urea nitrogen (BUN). Two-sample refers to the fact that the instrument-exposure and instrument-outcome estimate are obtained from two different genome-wide association studies (GWAS), in this case serving to increase the statistical power of the MR study.

Genetic variants for downregulated IL-6 signalling were selected as uncorrelated $\left(r^{2}<0.1\right)$ single-nucleotide polymorphism (SNPs) within $300 \mathrm{kB}$ of the IL-6 receptor gene (IL6R, GRCh37/hg19 coordinates: chr1:154,077,669 - 154,741,926) that associated with CRP in the UK Biobank ${ }^{12}(\mathrm{n}=337,199$, White British ancestry individuals) at genome-wide significance $(\mathrm{p}<5 \mathrm{E}-8)$. CRP is a reliable downstream marker for IL-6 signalling and thus, variants in the IL6R gene which associate with CRP levels represent proxies for IL-6 signalling modulation. To further investigate the validity of the selected variants, we measured the Pearson coefficient for the correlation between their association with CRP and other markers of IL-6 signalling, IL6R and serum IL-6 levels, obtained from an independent GWAS. ${ }^{13}$ The variance in CRP levels explained by the genetic variants, $\mathrm{R}^{2}$, was calculated using the formula: $\mathrm{R}^{2}=\left[2 \times \mathrm{MAF} \times(1-\mathrm{MAF}) \times \beta^{2}\right]$ where MAF is the minor allele frequency and $\beta$ is the effect estimate of the SNP on CRP levels. F-statistics, a measure of instrument strength in MR, were calculated using the formula: $\mathrm{F}=R^{2} \times(N-2) /\left(1-R^{2}\right)$ where $\mathrm{N}$ the number of individuals in the GWAS analysis.

Summary GWAS data from the Chronic Kidney Disease Genetics (CKDGen) Consortium European ancestry meta-analyses were used to obtain genetic association estimates for the primary outcomes of log eGFR, BUN and CKD (table 1). ${ }^{14}$ There are no overlapping populations between the exposure and outcome GWAS. In the original study, log eGFR was calculated using the Chronic Kidney Disease Epidemiology Collaboration (CKD-EPI) equation in adults and using the Schwartz formula for participants who were 18 years or younger. CKD was constructed as a binary outcome based on an eGFR $<60 \mathrm{ml} \mathrm{min}^{-1}$ per $1.73 \mathrm{~m}^{2}$. BUN was calculated as $2.8 \mathrm{x}$ blood urea $(\mathrm{mg} / \mathrm{dl})$. Power was calculated using the online tool (https://shiny.cnsgenomics.com/mRnd), to estimate the minimum and maximum effects that we had $80 \%$ statistical power to detect. 
Data for the exposure and outcome were harmonised according to the effect allele and no exclusions were made for palindromic variants. Individual MR estimates were calculated using the Wald Ratio. Heterogeneity was assessed using Cochran's Q statistic and to account for heterogeneity, a random-effects inverse-variance weighted method was used for the primary MR analysis. To explore potential pleiotropy, we conducted sensitivity analyses using the simple median, weighted median and MR-Egger methods. The median methods are robust if less than $50 \%$ of the contribution to the MR estimates coming from invalid instrumental variables. ${ }^{15}$ MR-Egger provides robust estimates even when all instrumental variables are invalid, as long as the INstrument Strength Independent of Direct Effect (INSIDE) assumption holds - that any pleiotropic effect of the variants on the outcome are independent of the strength of their association with the exposure. ${ }^{15}$ The estimated MR-Egger intercept is indicative of the average pleiotropic effect of the variants used. ${ }^{15}$ We tested for such pleiotropy by assessing whether our intercept was significantly different from zero. ${ }^{15}$ Results are presented as effect estimates and corresponding 95\% confidence intervals per standard deviation decrease in CRP levels. For eGFR and BUN respectively, estimates represent the change in log eGFR or blood urea nitrogen, and for CKD the results are expressed as odds ratio for CKD. All data analyses were performed using "TwoSampleMR" package version 4.26 in $\mathrm{R}$ statistical software.

In further sensitivity analysis, we repeated our analysis using a different set of instrumental variables that have been used in a previous study to proxy IL-6 signalling inhibition. ${ }^{16}$ These variants were selected based on associations with CRP $\left(\mathrm{p}<5 \mathrm{E}-8\right.$, clumped at $\left.\mathrm{r}^{2}<0.1\right)$ in the Cohorts for Heart and Aging Research in Genomic Epidemiology (CHARGE) Inflammation Working Group GWAS of 204,402 individuals of European ancestry. ${ }^{17}$ Data from UK Biobank was chosen for the primary analysis because there was overlapping studies between exposure and outcome data sources. 


\section{Results}

Thirty SNPs were used as instrumental variables to represent genetically proxied inhibition of IL-6 signalling (Table 2). The F-statistic for the genetic exposure associations ranged between 40.28 and 1713.82 (median F-statistic 98.0), indicating strong associations between the IL6-R variants and CRP level (Table 2). The genetic association with CRP in the UK Biobank showed a high degree of correlation with other markers of IL-6 signalling; IL6R ( $\mathrm{r}=$ $-0.90, p=1.75 \mathrm{E}-11)$ and serum IL-6 levels $(\mathrm{r}=-0.80, \mathrm{p}=6.2 \mathrm{E}-4$, Appendix 1$)$.

In the main analysis, there was no strong evidence for an association of genetically proxied inhibition of IL-6 inhibition with log eGFR (0.001, 95\% confidence interval -0.004 - 0.007), BUN $(0.009,95 \%$ confidence interval -0.003 - 0.021) and CKD (odds ratio 0.948, 95\% confidence interval $0.822-1.094)$. The results were consistent across all considered measures of renal function (Figure 1). There was evidence of heterogeneity in the main MR analyses for eGFR and CKD, but no heterogeneity for BUN (Appendix 2). The MR-Egger intercepts did not identify evidence of pleiotropy for eGFR, BUN or CKD ( $p=0.912, p=$ 0.798 and $p=0.681$ respectively). Individual SNP associations are provided in Appendix 3. Similar results were obtained in sensitivity analyses using instrumental variables obtained from the CHARGE consortium (Appendix 5).

\section{Discussion}

This MR study did not identify evidence to support that genetically proxied inhibition of IL-6 signalling has an effect on renal function. IL-6 inhibitors such as tocilizumab are currently licenced for use in rheumatoid arthritis, juvenile arthritis and more recently are under investigation for treatment of excessive inflammation in patients with severe acute respiratory syndrome coronavirus 2 infection. ${ }^{18}$ Atherosclerotic cardiovascular disease is an inflammatory disorder and both MR studies and randomised controlled trials suggest that inhibition of IL-6 signalling reduces risk of cardiovascular outcomes and thromboembolic events. ${ }^{16,19}$ Given the disproportionate burden of cardiovascular disease in patients with CKD and the inflammatory nature of both these conditions, there is growing interest in repurposing IL-6 inhibitors to treat CVD in CKD. ${ }^{10}$ Our current findings support that pharmacological IL6 inhibition would be unlikely to have a direct adverse effect on renal function. 
The findings of this MR study are in line with an earlier study of renal function in patients with rheumatoid arthritis and renal insufficiency receiving tocilizumab therapy. ${ }^{20}$ However, this observational study is small (120 participants), had large numbers of patient stopping or switching therapy (60\% switching biological therapy) and may be susceptible to confounding factors (patients receiving IL-6 inhibition were older and had rheumatoid arthritis for longer). ${ }^{20}$ More recently, the Il-1 $\beta$ inhibitor canakinumab, which also inhibits IL-6, was trialled in patients with CKD and showed no effect on renal function in terms of serial eGFR, creatinine and urinary albumin-creatinine ratio. ${ }^{8}$ The present MR study adds support to the initial pharmacovigilance surveys, and further is less prone to confounding and reverse causation. The manufacturer of tocilizumab (tradename: Actemra) advises that no dose adjustment is required for patients with mild renal impairment, however, cautions that the drug has not been studied in patients with moderate to severe renal dysfunction. ${ }^{21}$ This highlights a potential limitation of available clinical trial data - despite over $10 \%$ of patients in the developed world having renal impairment, patients with CKD are excluded from up to $75 \%$ of all randomised-controlled trials. ${ }^{22}$ MR may help in evaluating the safety of drugs insilico prior to trials in patients. For example, MR drug safety studies have in the past substantiated the causal relationship between inhibition of IL-6 signalling and increased risk of pneumonia. ${ }^{18}$ Furthermore, MR can provide more immediate drug safety information compared to usual pharmacovigilance strategies, such as the Medicines and Healthcare Products Regulatory Agency yellow card scheme.

Our study has a number of strengths. In an attempt to minimise the bias related to pleiotropic effects of variants, instrumental variables were selected based on their proximity to the IL6R gene and in relation to reliable biomarkers of IL- 6 signalling. In addition, the MR-Egger method did not provide evidence to suggest biasing pleiotropy. Our results were robust to sensitivity analysis where different SNPs to proxy IL-6 signalling inhibition were selected from an independent GWAS. Furthermore, the consistency of our results across different MR methods and different measurements of renal dysfunction further substantiates the null findings.

Our study also has limitations. The analysis for eGFR was well-powered and it is unlikely that the null finding for eGFR represents a type II error for a clinically relevant effect. There was less power to detect small differences for BUN and CKD due to the smaller number of participants or cases, respectively, in the GWAS. It is important to interpret our findings 
within the context of an MR study, which considers genetically proxied inhibition of IL-6 signalling, rather than the effect of a discrete clinical intervention. Our approach looks at IL-6 signalling in isolation, and it is possible that pharmacological IL-6 inhibitors could have offtarget effects (aside from IL-6R signalling) on other renal or extra-renal pathways which may ameliorate or exacerbate renal function indirectly. There are also the possibility of drug-drug interactions that cannot be accounted for in the present MR analysis.

In conclusion, this study is consistent with the hypothesis that inhibition of IL-6 signalling does not directly affect renal function, supporting this approach as a therapeutic opportunity for reducing the risk of CVD in patients with CKD.

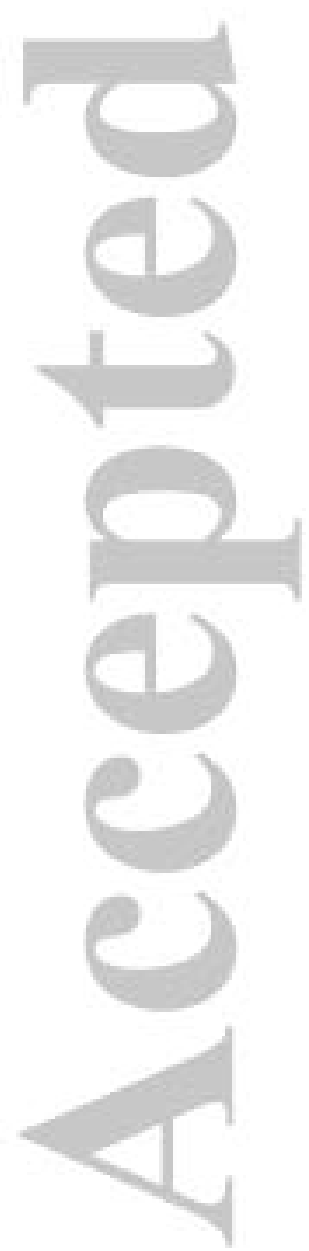




\section{References}

1. Longenecker JC, Coresh J, Powe NR, Levey AS, Fink NE, Martin A, et al. Traditional cardiovascular disease risk factors in dialysis patients compared with the general population: the CHOICE Study. J Am Soc Nephrol [Internet]. 2002 Jul 1 [cited 2020 Sep 24];13(7):1918-27. Available from:

http://www.ncbi.nlm.nih.gov/pubmed/10703676

2. Herzog CA, Asinger RW, Berger AK, Charytan DM, Díez J, Hart RG, et al. Cardiovascular disease in chronic kidney disease. A clinical update from Kidney Disease: Improving Global Outcomes (KDIGO). Kidney Int [Internet]. 2011 Sep 2 [cited 2020 Sep 24];80(6):572-86. Available from: https://www.sciencedirect.com/science/article/pii/S0085253815551053

3. Spoto B, Mattace-Raso F, Sijbrands E, Leonardis D, Testa A, Pisano A, et al. Association of IL-6 and a functional polymorphism in the IL-6 gene with cardiovascular events in patients with CKD. Clin J Am Soc Nephrol [Internet]. 2015 Feb 6 [cited 2020 Sep 24];10(2):232-40. Available from: http://www.ncbi.nlm.nih.gov/pubmed/25492254

4. Libby P, Ridker PM, Hansson GK. Inflammation in Atherosclerosis: From Pathophysiology to Practice. J Am Coll Cardiol [Internet]. 2009 Dec 1 [cited 2020 Sep 24];54(23):2129-38. Available from: https://www.sciencedirect.com/science/article/pii/S073510970903006X

5. Zoccali C, Mallamaci F, Tripepi G. Inflammatory proteins as predictors of cardiovascular disease in patients with end-stage renal disease. Nephrol Dial Transplant [Internet]. 2004 Aug 1 [cited 2020 Sep 24];19(suppl_5):v67-72. Available from: https://academic.oup.com/ndt/article-lookup/doi/10.1093/ndt/gfh1059

6. Bermudez EA, Rifai N, Buring J, Manson JE, Ridker PM. Interrelationships Among Circulating Interleukin-6, C-Reactive Protein, and Traditional Cardiovascular Risk Factors in Women. Arterioscler Thromb Vasc Biol [Internet]. 2002 Oct [cited 2020 Sep 24];22(10):1668-73. Available from:

https://www.ahajournals.org/doi/10.1161/01.ATV.0000029781.31325.66

7. Honda H, Qureshi AR, Heimbürger O, Barany P, Wang K, Pecoits-Filho R, et al. Serum albumin, C-reactive protein, interleukin 6, and fetuin a as predictors of malnutrition, cardiovascular disease, and mortality in patients with ESRD. Am J Kidney Dis [Internet]. 2006 Jan [cited 2020 Sep 24];47(1):139-48. Available from: http://www.ncbi.nlm.nih.gov/pubmed/16377395 
8. Ridker PM, MacFadyen JG, Glynn RJ, Koenig W, Libby P, Everett BM, et al. Inhibition of Interleukin- $1 \beta$ by Canakinumab and Cardiovascular Outcomes in Patients With Chronic Kidney Disease. J Am Coll Cardiol [Internet]. 2018 May 29 [cited 2020 Dec 4];71(21):2405-14. Available from:

https://www.sciencedirect.com/science/article/pii/S0735109718342712?via\%3Dihub

9. Ridker PM, Libby P, MacFadyen JG, Thuren T, Ballantyne C, Fonseca F, et al. Modulation of the interleukin-6 signalling pathway and incidence rates of atherosclerotic events and all-cause mortality: analyses from the Canakinumab AntiInflammatory Thrombosis Outcomes Study (CANTOS). Eur Heart J [Internet]. 2018 [cited 2020 Dec 4];39(38):3499-507. Available from:

http://www.ncbi.nlm.nih.gov/pubmed/30165610

10. Kakkar R, Lo L, Kling D, Devalaraja M, Davidson M. Effects of Ziltivekimab (ZILTI), a Novel Anti-Interleukin-6 Monoclonal Antibody, on Markers of Inflammation and Cardiovascular Risk in Patients With Chronic Kidney Disease on Hemodialysis. Circulation. 2019;

11. Davies NM, Holmes M V, Davey Smith G. Reading Mendelian randomisation studies: a guide, glossary, and checklist for clinicians. BMJ [Internet]. 2018 Jul 12 [cited 2020 Sep 24];362:k601. Available from: http://www.ncbi.nlm.nih.gov/pubmed/30002074

12. Neale B. Rapid GWAS of thousands of phenotypes in the UK Biobank 2020. Available from: http://www.nealelab.is/uk-biobank/ukbround2announcement.

13. Sun BB, Maranville JC, Peters JE, Stacey D, Staley JR, Blackshaw J, et al. Genomic atlas of the human plasma proteome. Nature [Internet]. 2018 Jun 6 [cited 2020 Dec 4];558(7708):73-9. Available from: http://www.nature.com/articles/s41586-018-01752

14. Wuttke M, Li Y, Li M, Sieber KB, Feitosa MF, Gorski M, et al. A catalog of genetic loci associated with kidney function from analyses of a million individuals. Nat Genet [Internet]. 2019 Jun [cited 2020 Sep 24];51(6):957-72. Available from: http://www.nature.com/articles/s41588-019-0407-x

15. Burgess $\mathrm{S}$, Thompson SG. Interpreting findings from Mendelian randomization using the MR-Egger method. Eur J Epidemiol [Internet]. 2017 May 19 [cited 2020 Sep 24];32(5):377-89. Available from: http://link.springer.com/10.1007/s10654-017-0255$\mathrm{X}$

16. Georgakis MK, Malik R, Gill D, Franceschini N, Sudlow CLM, Dichgans M, et al. Interleukin-6 Signaling Effects on Ischemic Stroke and Other Cardiovascular 
Outcomes: A Mendelian Randomization Study. Circ Genomic Precis Med [Internet]. 2020 Jun [cited 2020 Sep 24];13(3):e002872. Available from:

https://www.ahajournals.org/doi/10.1161/CIRCGEN.119.002872

17. Ligthart S, Vaez A, Võsa U, Stathopoulou MG, de Vries PS, Prins BP, et al. Genome Analyses of >200,000 Individuals Identify 58 Loci for Chronic Inflammation and Highlight Pathways that Link Inflammation and Complex Disorders. Am J Hum Genet [Internet]. 2018 Nov 1 [cited 2020 Sep 24];103(5):691-706. Available from: https://www.sciencedirect.com/science/article/pii/S0002929718303203

18. Larsson SC, Burgess S, Gill D. Genetically proxied interleukin-6 receptor inhibition: opposing associations with COVID-19 and pneumonia. Eur Respir J [Internet]. 2020 Nov 19 [cited 2020 Dec 10]; Available from: http://www.ncbi.nlm.nih.gov/pubmed/33214204

19. Ridker PM, Everett BM, Thuren T, MacFadyen JG, Chang WH, Ballantyne C, et al. Antiinflammatory Therapy with Canakinumab for Atherosclerotic Disease. N Engl J Med [Internet]. 2017 Sep 21 [cited 2020 Sep 24];377(12):1119-31. Available from: http://www.nejm.org/doi/10.1056/NEJMoa1707914

20. Mori S, Yoshitama T, Hidaka T, Hirakata N, Ueki Y. Effectiveness and safety of tocilizumab therapy for patients with rheumatoid arthritis and renal insufficiency: a real-life registry study in Japan (the ACTRA-RI study). Ann Rheum Dis [Internet]. 2015 Mar [cited 2020 Sep 24];74(3):627-30. Available from: http://www.ncbi.nlm.nih.gov/pubmed/25561361

21. Food and Drug Administration U. FDA: Tocilizumab (Actemra) Product Information Sheet [Internet]. 2013. [cited 2020 Sep 24]. Available from: https://www.accessdata.fda.gov/drugsatfda_docs/label/2013/125276s092lbl.pdf

22. Charytan D, Kuntz RE. The exclusion of patients with chronic kidney disease from clinical trials in coronary artery disease. Kidney Int [Internet]. 2006 Dec [cited 2020 Sep 24];70(11):2021-30. Available from: http://www.ncbi.nlm.nih.gov/pubmed/17051142

23. Kamat MA, Blackshaw JA, Young R, Surendran P, Burgess S, Danesh J, et al. PhenoScanner V2: an expanded tool for searching human genotype-phenotype associations. Kelso J, editor. Bioinformatics [Internet]. 2019 Nov 1 [cited 2020 Dec 4];35(22):4851-3. Available from: https://academic.oup.com/bioinformatics/article/35/22/4851/5522366 
Table 1:

Data sources for exposure and outcomes

\begin{tabular}{|c|c|c|c|c|c|}
\hline Data & Data Source & $\begin{array}{l}\text { Population } \\
\text { Ancestry }\end{array}$ & Sample size & Exposure definition & Adjustments \\
\hline $\begin{array}{l}\text { Blood urea nitrogen } \\
\text { (BUN) }\end{array}$ & $\begin{array}{l}\text { Chronic Kidney } \\
\text { Disease Genetics } \\
\text { Consortium meta- } \\
\text { analysis ( } \mathrm{n}=24 \\
\text { studies) }^{14}\end{array}$ & European & 243,029 & $\begin{array}{l}\text { Change in BUN } \\
(\mathrm{mg} / \mathrm{dL}) \text { per copy } \\
\text { increment of effect } \\
\text { allele }\end{array}$ & \multirow{2}{*}{$\begin{array}{l}\text { Sex and age in all included } \\
\text { studies, with some studies } \\
\text { in the meta-analysis } \\
\text { further adjusting for study } \\
\text { site, relatedness, and } \\
\text { principal components of } \\
\text { genetic ancestry. }\end{array}$} \\
\hline $\begin{array}{l}\text { Estimated } \\
\text { glomerular filtration } \\
\text { rate }(\mathrm{eGFR})\end{array}$ & $\begin{array}{l}\text { Chronic Kidney } \\
\text { Disease Genetics } \\
\text { Consortium meta- } \\
\text { analysis ( } \mathrm{n}=42 \\
\text { studies) }^{14}\end{array}$ & European & 567,460 & $\begin{array}{l}\text { Change in log eGFR } \\
\left(\mathrm{ml} \text { min- }{ }^{1} \text { per } 1.73 \mathrm{~m}^{2}\right) \\
\text { per copy increment of } \\
\text { effect allele }\end{array}$ & \\
\hline
\end{tabular}

Table 1 describes the source, population ancestry, sample size and exposure definitions for the genome-wide association studies used in the present Mendelian randomization analysis. 
Table 2:

Instrumental variables: Variants employed as instrumental variables to proxy inhibition of IL-6 signalling. Associations with C-reactive protein are detailed.

\begin{tabular}{|c|c|c|c|c|c|c|c|c|}
\hline SNP & \begin{tabular}{|l|} 
Effect \\
Allele \\
\end{tabular} & \begin{tabular}{|l|} 
Other \\
Allele \\
\end{tabular} & \begin{tabular}{|l|} 
Effect Allele \\
Frequency \\
\end{tabular} & Beta & Standard Error & $P$ value & $\mathbf{R}^{2}$ & $\mathbf{F}$ \\
\hline rs112505856 & $\mathrm{T}$ & $\mathrm{C}$ & 0.039 & -0.046 & 0.006 & $8.82 \mathrm{E}-13$ & $1.58 \mathrm{E}-04$ & 74.48 \\
\hline rs16835819 & $\mathrm{C}$ & $\mathrm{T}$ & 0.018 & -0.077 & 0.009 & $7.73 \mathrm{E}-18$ & $2.15 \mathrm{E}-04$ & 101.05 \\
\hline rs61806853 & $\mathrm{C}$ & $\mathrm{T}$ & 0.050 & -0.044 & 0.006 & $2.26 \mathrm{E}-15$ & $1.79 \mathrm{E}-04$ & 84.22 \\
\hline rs79505546 & $\mathrm{T}$ & $\mathrm{C}$ & 0.017 & -0.054 & 0.009 & 7.21E-09 & $9.62 \mathrm{E}-05$ & 45.2 \\
\hline rs1194610 & $\mathrm{C}$ & $\mathrm{T}$ & 0.235 & 0.020 & 0.003 & $6.01 \mathrm{E}-13$ & $1.48 \mathrm{E}-04$ & 69.47 \\
\hline rs67156297 & A & $\mathrm{G}$ & 0.262 & 0.036 & 0.003 & $9.96 \mathrm{E}-40$ & $4.97 \mathrm{E}-04$ & 233.76 \\
\hline rs12077265 & $\mathrm{G}$ & $\mathrm{T}$ & 0.155 & -0.056 & 0.003 & $6.24 \mathrm{E}-64$ & $8.20 \mathrm{E}-04$ & 385.54 \\
\hline rs4133213 & $\mathrm{A}$ & C & 0.450 & -0.086 & 0.003 & $1.00 \mathrm{E}-200$ & $3.63 \mathrm{E}-03$ & 1713.82 \\
\hline rs79219014 & $\mathrm{T}$ & $\mathrm{G}$ & 0.028 & -0.086 & 0.007 & $1.26 \mathrm{E}-31$ & 3.92E-04 & 184.24 \\
\hline rs186110340 & $G$ & $\mathrm{C}$ & 0.024 & 0.056 & 0.008 & $5.02 \mathrm{E}-12$ & $1.48 \mathrm{E}-04$ & 69.61 \\
\hline rs139952834 & $\mathrm{T}$ & $\mathrm{C}$ & 0.013 & 0.062 & 0.011 & $3.36 \mathrm{E}-08$ & $9.84 \mathrm{E}-05$ & 46.23 \\
\hline rs113580743 & 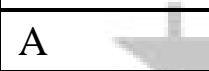 & G & 0.039 & 0.049 & 0.006 & $4.12 \mathrm{E}-15$ & \begin{tabular}{|l|}
$1.81 \mathrm{E}-04$ \\
\end{tabular} & 85.11 \\
\hline rs139460294 & $\mathrm{C}$ & $\mathrm{T}$ & 0.016 & -0.059 & 0.010 & $4.48 \mathrm{E}-09$ & $1.06 \mathrm{E}-04$ & 49.83 \\
\hline rs140615642 & $\mathrm{C}$ & $\mathrm{T}$ & 0.020 & -0.078 & 0.009 & $8.53 \mathrm{E}-19$ & \begin{tabular}{|l|}
$2.37 \mathrm{E}-04$ \\
\end{tabular} & 111.53 \\
\hline rs116059394 & $\mathrm{G}$ & $\mathrm{A}$ & 0.059 & 0.049 & \begin{tabular}{|l|}
0.005 \\
\end{tabular} & $8.73 \mathrm{E}-21$ & $2.60 \mathrm{E}-04$ & \begin{tabular}{|l|}
122.33 \\
\end{tabular} \\
\hline rs56100876 & $\mathrm{A}$ & $\mathrm{G}$ & 0.019 & -0.109 & 0.009 & $2.35 \mathrm{E}-33$ & 4.41E-04 & \begin{tabular}{|l|}
207.24 \\
\end{tabular} \\
\hline rs4845645 & $\mathrm{A}$ & $\mathrm{T}$ & 0.173 & -0.051 & 0.003 & $1.31 \mathrm{E}-55$ & \begin{tabular}{|l|}
$7.34 \mathrm{E}-04$ \\
\end{tabular} & 344.98 \\
\hline rs77994623 & $\mathrm{T}$ & $\mathrm{C}$ & 0.167 & 0.047 & 0.003 & $7.08 \mathrm{E}-49$ & $6.16 \mathrm{E}-04$ & \begin{tabular}{|l|}
289.57 \\
\end{tabular} \\
\hline rs76289529 & $\mathrm{T}$ & $\mathrm{C}$ & 0.038 & -0.047 & 0.006 & $8.22 \mathrm{E}-14$ & $1.64 \mathrm{E}-04$ & 76.86 \\
\hline rs12750774 & $\mathrm{A}$ & $\mathrm{G}$ & 0.316 & -0.064 & 0.003 & $1.33 \mathrm{E}-137$ & $1.77 \mathrm{E}-03$ & 834.94 \\
\hline
\end{tabular}




\begin{tabular}{|c|c|c|c|c|c|c|c|c|}
\hline rs147483024 & $\mathrm{T}$ & G & 0.018 & 0.066 & 0.010 & $7.47 \mathrm{E}-12$ & $1.55 \mathrm{E}-04$ & 73.01 \\
\hline rs3766925 & $\mathrm{A}$ & $\mathrm{T}$ & 0.227 & -0.016 & 0.003 & 4.12E-08 & $8.57 \mathrm{E}-05$ & 40.28 \\
\hline rs12059682 & $\mathrm{C}$ & $\mathrm{T}$ & 0.206 & 0.046 & 0.003 & $5.39 \mathrm{E}-55$ & $6.97 \mathrm{E}-04$ & 327.51 \\
\hline rs188727323 & $\mathrm{T}$ & $\mathrm{C}$ & 0.189 & -0.044 & 0.003 & $5.35 \mathrm{E}-39$ & $5.80 \mathrm{E}-04$ & 272.64 \\
\hline rs4845657 & $\mathrm{C}$ & $\mathrm{T}$ & 0.199 & 0.040 & 0.003 & $1.49 \mathrm{E}-39$ & $5.03 \mathrm{E}-04$ & 236.5 \\
\hline rs12757447 & $\mathrm{G}$ & $\mathrm{T}$ & 0.016 & -0.063 & 0.010 & $1.43 \mathrm{E}-10$ & $1.23 \mathrm{E}-04$ & 58 \\
\hline rs79753070 & $\mathrm{A}$ & $\mathrm{G}$ & 0.025 & -0.052 & 0.008 & $8.96 \mathrm{E}-11$ & $1.29 \mathrm{E}-04$ & 60.64 \\
\hline rs34693607 & $\mathrm{G}$ & $\mathrm{C}$ & 0.214 & -0.033 & 0.003 & $2.09 \mathrm{E}-29$ & $3.62 \mathrm{E}-04$ & 170.15 \\
\hline rs11264245 & $\mathrm{T}$ & $\mathrm{C}$ & 0.057 & -0.029 & 0.005 & $3.12 \mathrm{E}-08$ & $8.78 \mathrm{E}-05$ & 41.25 \\
\hline rs7523010 & $\mathrm{A}$ & $\mathrm{T}$ & 0.213 & 0.025 & 0.003 & $2.13 \mathrm{E}-15$ & $2.02 \mathrm{E}-04$ & 94.96 \\
\hline
\end{tabular}

Table 2 shows the summary data for the variants that proxy IL-6 signalling inhibition. SNP: single-nucleotide polymorphism. Beta is the standard deviation unit change in CRP $(4.35 \mathrm{mg} / \mathrm{L})$ per copy increment in the effect allele. $\mathrm{R}^{2}$ represents the variance in CRP explained by the respective genetic variant. F-statistic measures the strength of the instrumental variable with the exposure. In an additive model assuming independent variants, these instrumental variables explain 0.0138 of the variance in the exposure. 


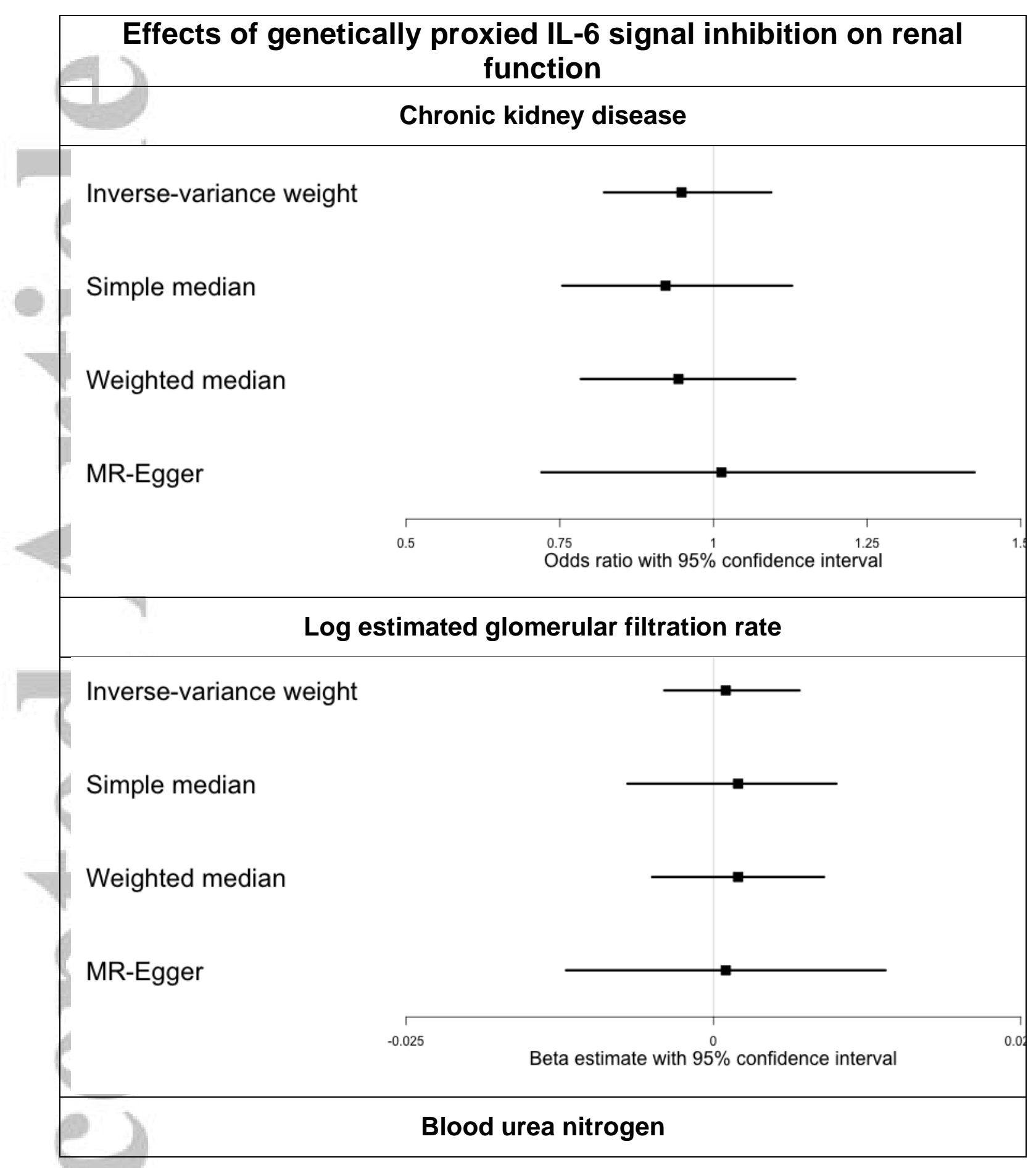

This article is protected by copyright. All rights reserved. 


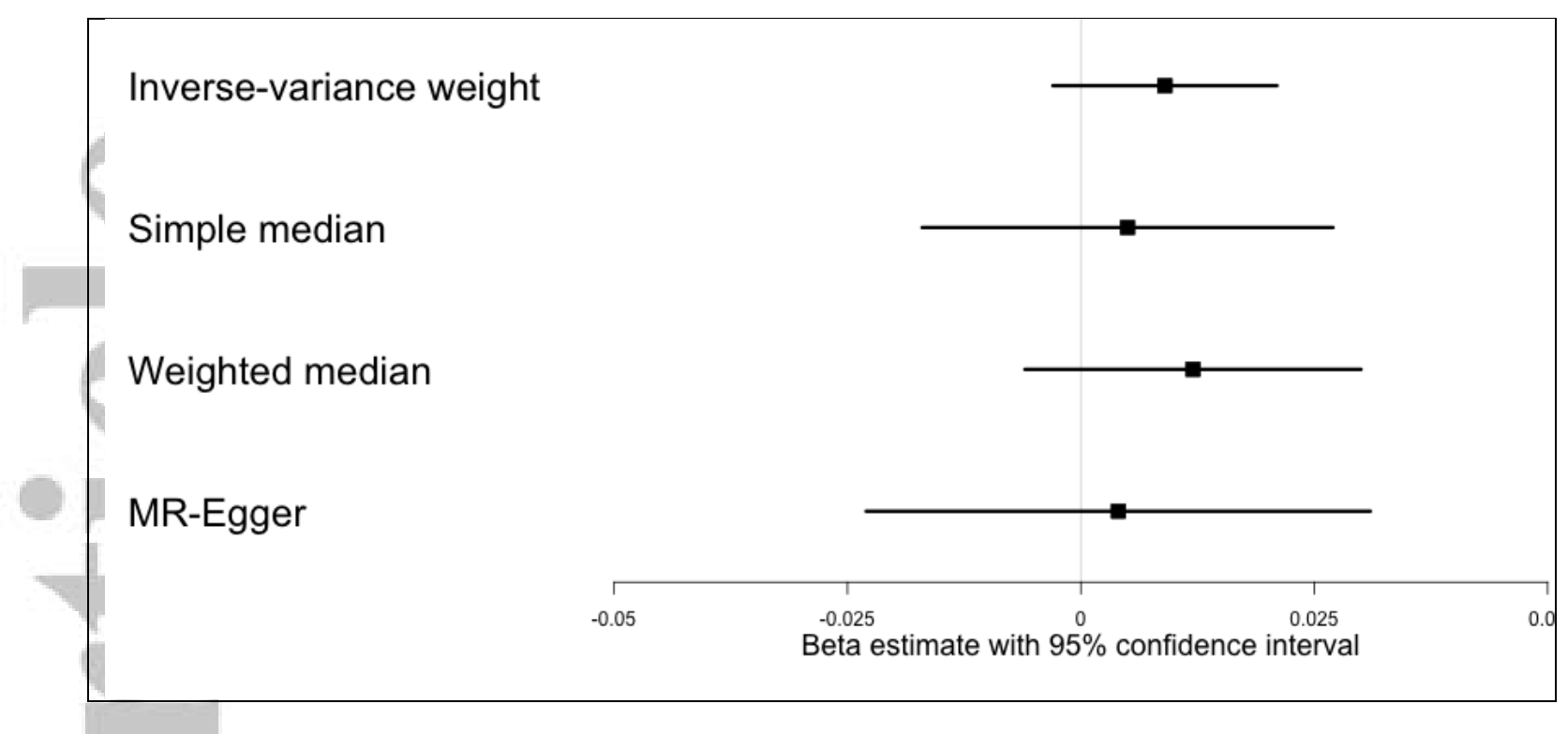

Forest plots showing the Mendelian randomization estimates for chronic kidney disease (CKD), log eGFR (estimated glomerular filtration rate) and blood urea nitrogen (BUN) with different methods (simple median, weighted median, inverse-variance weighted, MR-Egger). eGFR and BUN are presented as causal estimates with $95 \%$ confidence interval. CKD is described as the odds ratio (95\% confidence interval) of having CKD. Full results table and individual Wald ratio estimates described are in the Appendix.

Figure 1: Effects of genetically proxied IL-6 signal inhibition on renal function 
Appendix 1: Genetic proxies for interleukin 6 (IL-6) inhibition selected on basis of their association with C-reactive protein (CRP), and the corresponding associations with soluble interleukin 6 receptor and serum IL-6

\begin{tabular}{|c|c|c|c|c|c|}
\hline SNP & $\begin{array}{l}\text { Effect } \\
\text { Allele }\end{array}$ & Other Allele & $\begin{array}{l}\text { Beta estimate for } \\
\text { association with CRP } \\
\text { (UK Biobank) }\end{array}$ & $\begin{array}{l}\text { Beta estimate for association with } \\
\text { IL6R (INTERVAL Study) }\end{array}$ & $\begin{array}{l}\text { Beta estimate for association with } \\
\text { serum IL-6 (INTERVAL STUDY) }\end{array}$ \\
\hline rs112505856 & $\mathrm{T}$ & $\mathrm{C}$ & -0.046 & 0.316 & \\
\hline rs 16835819 & $\mathrm{C}$ & $\mathrm{T}$ & -0.077 & 0.453 & \\
\hline rs61806853 & $\mathrm{C}$ & $\mathrm{T}$ & -0.044 & 0.496 & \\
\hline rs79505546 & $\mathrm{T}$ & $\mathrm{C}$ & -0.054 & 0.356 & \\
\hline rs1194610 & $\mathrm{C}$ & $\mathrm{T}$ & 0.020 & 0.190 & \\
\hline rs67156297 & $\mathrm{A}$ & G & 0.036 & -0.254 & -0.254 \\
\hline rs12077265 & G & $T$ & -0.056 & -0.075 & -0.044 \\
\hline rs4133213 & $\mathrm{A}$ & $\mathrm{C}$ & -0.086 & 0.974 & 0.084 \\
\hline rs79219014 & $\mathrm{T}$ & G & -0.086 & 0.758 & 0.087 \\
\hline rs186110340 & $\mathrm{G}$ & C & 0.056 & -0.548 & \\
\hline rs139952834 & $\mathrm{T}$ & $\mathrm{C}$ & 0.062 & -0.651 & \\
\hline rs113580743 & $\mathrm{A}$ & G & 0.049 & -0.514 & \\
\hline rs139460294 & $\mathrm{C}$ & $T$ & -0.058 & 0.384 & 0.136 \\
\hline rs140615642 & $\mathrm{C}$ & $\mathrm{T}$ & -0.078 & 0.547 & \\
\hline rs116059394 & G & A & 0.048 & -0.576 & -0.064 \\
\hline rs56100876 & $\mathrm{A}$ & $\mathrm{G}$ & -0.109 & 0.584 & \\
\hline rs4845645 & A & $\mathrm{T}$ & -0.051 & 0.219 & 0.082 \\
\hline rs 77994623 & $\mathrm{~T}$ & $\mathrm{C}$ & 0.047 & -0.618 & \\
\hline rs76289529 & $\mathrm{T}$ & $\mathrm{C}$ & -0.047 & 0.666 & 0.107 \\
\hline
\end{tabular}




\begin{tabular}{|l|l|l|l|l|l|}
\hline rs12750774 & A & G & -0.064 & 0.549 & 0.057 \\
\hline rs147483024 & T & G & 0.066 & -0.308 & -0.156 \\
\hline rs3766925 & A & T & -0.016 & 0.184 & -0.049 \\
\hline rs12059682 & C & T & 0.046 & -0.383 & -0.055 \\
\hline rs188727323 & T & C & -0.043 & & \\
\hline rs4845657 & C & T & 0.040 & -0.273 & \\
\hline rs12757447 & G & T & -0.063 & 0.253 & \\
\hline rs79753070 & A & G & -0.052 & 0.571 & 0.142 \\
\hline rs34693607 & G & C & -0.033 & 0.196 & 0.058 \\
\hline rs11264245 & T & C & -0.029 & 0.447 & \\
\hline rs7523010 & A & T & 0.025 & -0.049 & \\
\hline
\end{tabular}

Pearson correlations:

- Correlation between CRP and IL6R association: $r=-0.90, p=1.8 \mathrm{E}-11$

- Correlation between CRP and IL-6 association: $r=-0.80, p=6.2 \mathrm{E}-4$

Table showing the association between SNPs and CRP, IL-6 receptor and serum IL-6 level. SNP: single nucleotide polymorphism. Beta is the standard deviation unit change in CRP, IL-6 alpha subunit or IL-6 level per copy increment in the effect allele. The association between individual variants and CRP was established in the UK Biobank. Associations between individual variants and IL-6 receptor and serum IL-6 were obtained from the INTERVAL study ${ }^{13}$ as made publicly available through the PhenoScanner database ${ }^{23}$. Missing cells infer no data was available for the respective variant in the INTERVAL study. 
Appendix 2: Mendelian randomization sensitivity analysis estimates for the association of genetically proxied inhibition of IL-6 signalling with measures of renal function

Chronic Kidney Disease: effects of genetically proxied IL-6 inhibition on Chronic Kidney Disease

\begin{tabular}{|l|l|l|l|}
\hline Method & Estimate (standard error) & $\begin{array}{l}\text { Odds ratio } \\
\text { (95\% Confidence Interval) }\end{array}$ & P value \\
\hline Inverse-variance weighted & $-0.053(0.073)$ & $0.948(0.822-1.094)$ & 0.474 \\
\hline Simple median & $-0.081(0.103)$ & $0.922(0.754-1.128)$ & 0.431 \\
\hline Weighted median & $-0.059(0.094)$ & $0.943(0.784-1.133)$ & 0.528 \\
\hline MR-Egger & $0.013(0.174)$ & $1.013(0.720-1.425)$ & 0.942 \\
\hline MR-Egger intercept & $-0.004(0.174)$ & $0.996(0.708-1.401)$ & 0.681 \\
\hline
\end{tabular}

Cochran's Q-statistic:

Inverse-variance weighted analysis: 35.38 (SNPs: 27), $\mathrm{p}=0.13$

Log estimated glomerular filtration rate: association of genetically proxied inhibition of IL-6 signalling with log odds of estimated glomerular filtration rate

\begin{tabular}{|l|l|l|l|}
\hline Method & Estimate (standard error) & 95\% confidence interval & P value \\
\hline Inverse-variance weighted & $0.001(0.003)$ & $-0.004-0.007$ & 0.599 \\
\hline Simple median & $0.002(0.004)$ & $-0.007-0.010$ & 0.721 \\
\hline Weighted median & $0.002(0.004)$ & $-0.005-0.009$ & 0.620 \\
\hline MR-Egger & $0.001(0.007)$ & $-0.012-0.014$ & 0.908 \\
\hline MR-Egger intercept & $0.0004(0.0003)$ & $-0.0006-0.0007$ & 0.912 \\
\hline
\end{tabular}

Cochran's Q-statistic:

Inverse-variance weighted analysis: 37.93 (SNPs 27), $\mathrm{p}=0.08$

Blood urea nitrogen: effects of genetically proxied IL-6 inhibition on blood urea nitrogen

\begin{tabular}{|l|l|l|l|}
\hline Method & Estimate (standard error) & 95\% confidence interval & P value \\
\hline Inverse-variance weighted & $0.009(0.006)$ & $-0.003-0.021$ & 0.121 \\
\hline Simple median & $0.005(0.011)$ & $-0.017-0.027$ & 0.666 \\
\hline Weighted median & $0.012(0.009)$ & $-0.006-0.030$ & 0.183 \\
\hline MR-Egger & $0.004(0.014)$ & $-0.023-0.031$ & 0.798 \\
\hline MR-Egger Intercept & $0.0003(0.0007)$ & $-0.0016-0.001$ & 0.662 \\
\hline
\end{tabular}

Cochran's Q-statistic:

Inverse-variance weighted analysis: 22.24 (SNPs 25), $\mathrm{p}=0.62$

This article is protected by copyright. All rights reserved. 


\section{Appendix 3:}

Chronic Kidney Disease: associations of genetically proxied IL-6 inhibition on Chronic Kidney Disease for each instrumental variable

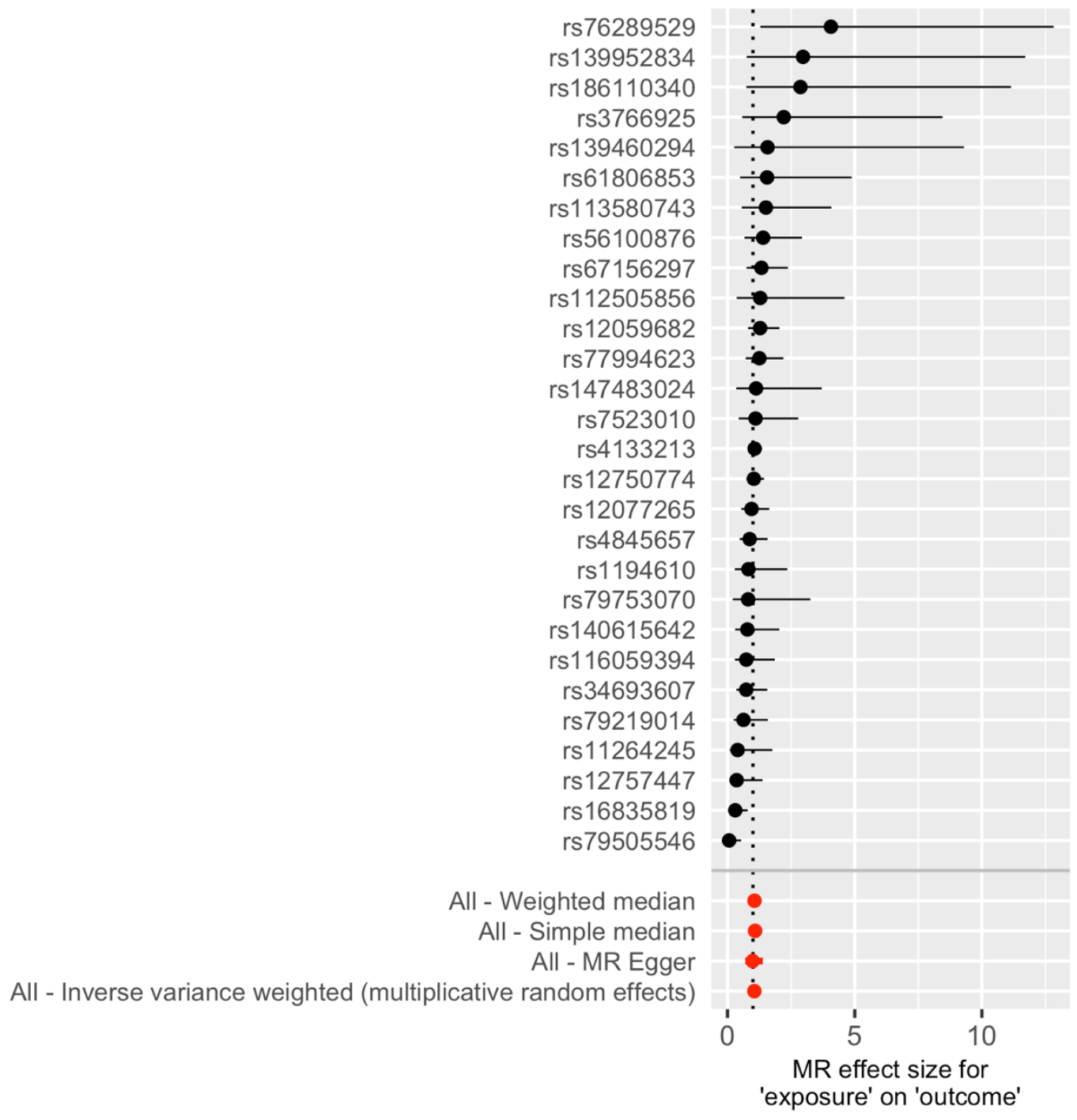

Forest plot showing the individual Wald ratios and 95\% confidence intervals for each variant used in the primary analysis. Pooled estimates using inverse-variance weighted, simple median, weighted median and MR-Egger are shown in red. 
Blood Urea Nitrogen: associations of genetically proxied IL-6 inhibition on blood urea nitrogen for each instrumental variable

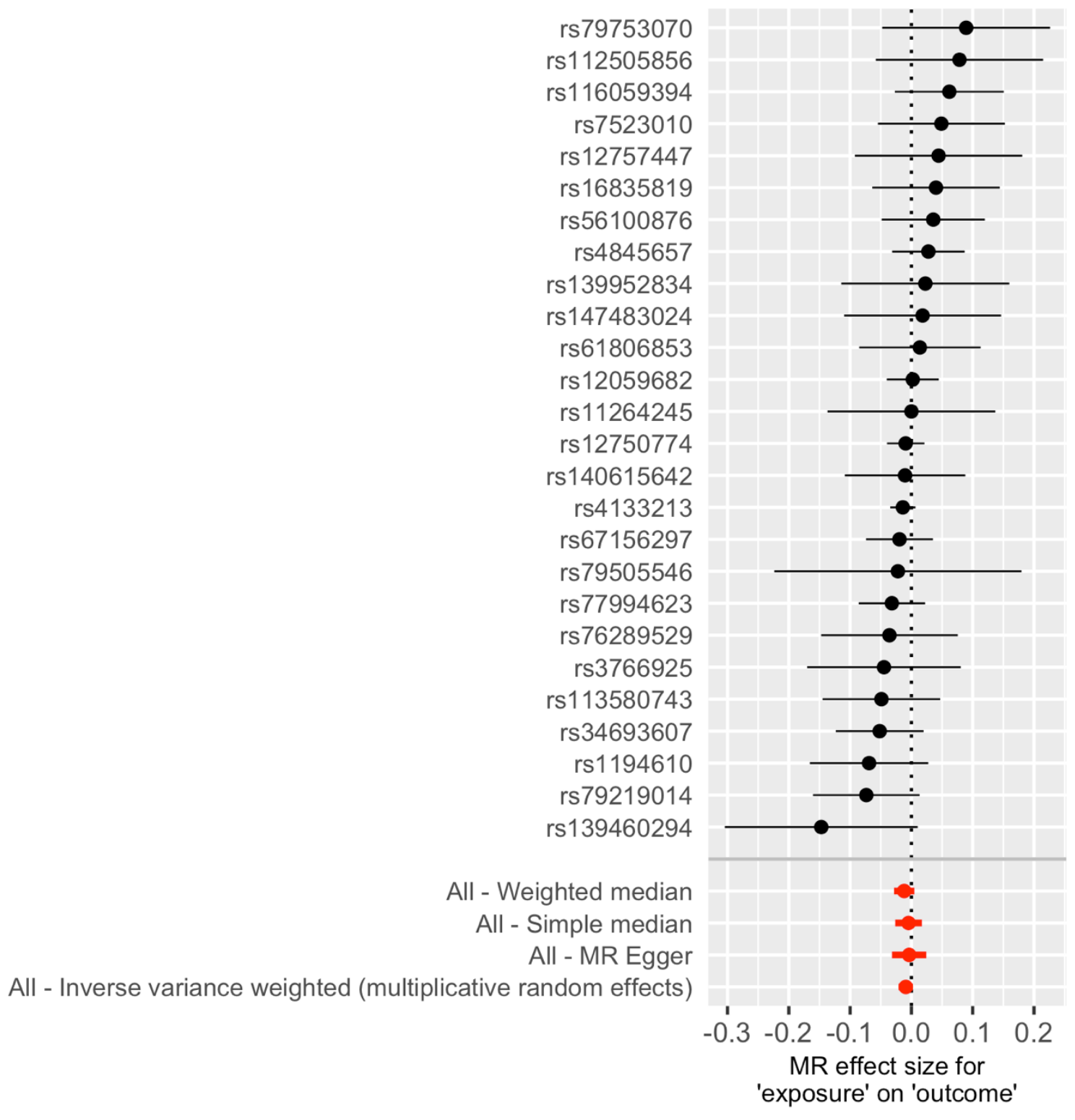

Forest plot showing the individual Wald ratios with 95\% confidence intervals for each variant used in the primary analysis. Pooled estimates using inverse-variance weighted, simple median, weighted median and MR-Egger are shown in red. 
Log estimated glomerular filtration rate (eGFR): associations of genetically proxied IL-6 inhibition on eGFR for each instrumental variable

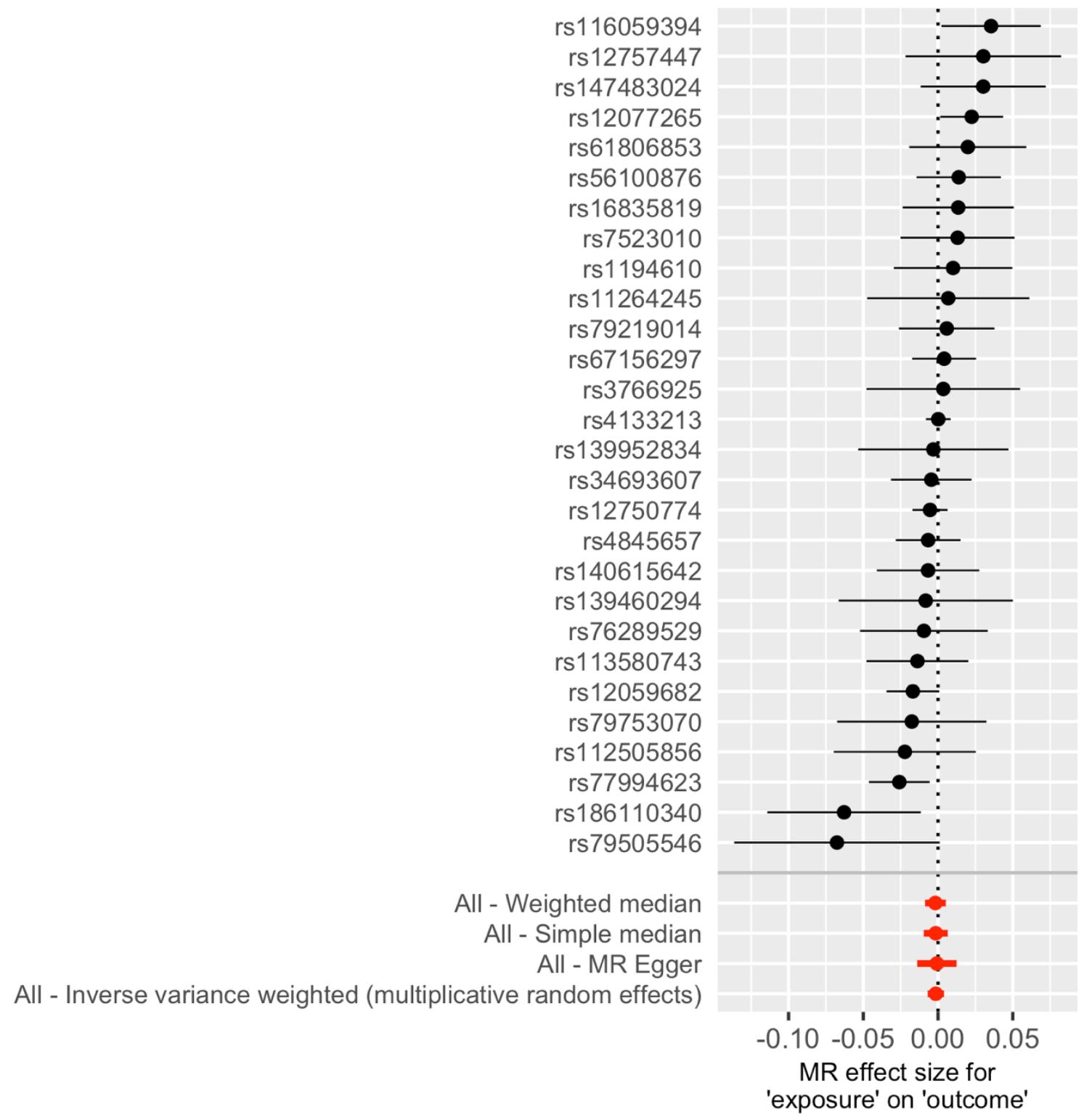

Forest plot showing the individual Wald ratios with $95 \%$ confidence intervals for each variant used in the primary analysis. Pooled estimates using inverse-variance weighted, simple median, weighted median and MR-Egger are shown in red. 
Appendix 4: Power calculations for the primary Mendelian randomisation analyses

\begin{tabular}{|l|l|l|}
\hline \multicolumn{2}{|l|}{ Continuous Outcomes } \\
\hline Phenotype & N total & Detectable MR-Estimate at 80\% power \\
\hline Log eGFR & 567,460 & $\leq-0.0000405, \geq 0.000034$ \\
\hline BUN & 243,029 & $\leq-0.0158, \geq 0.0157$ \\
\hline Categorical Outcomes & Detectable OR at $80 \%$ power \\
\hline Phenotype & N total $(\%$ cases $)$ & $\leq 0.879$ or $\geq 1.124$ \\
\hline CKD & $480,698(8.6 \%)$ & \\
\hline
\end{tabular}

Table detailing the minimum and maximum estimates that the primary analysis had $80 \%$ statistical power to detect. Power calculation were based on the online application: https://shiny.cnsgenomics.com/mRnd. The total variance explained by the variants was estimated using their total $\mathrm{R}^{2}$. 


\section{Appendix 5: Sensitivity Analysis}

Instrumental variables from the CHARGE Consortium: Variants employed as instrumental variables to proxy inhibition of IL-6 signalling. Associations with C-reactive protein are detailed. Instruments $(n=7)$ were selected by based on the association of variants within $300 \mathrm{kB}$ of the IL6R gene with CRP in the CHARGE GWAS. These were originally identified by Georgakis et al. ${ }^{16}$

\begin{tabular}{|c|c|c|c|c|c|c|c|c|}
\hline SNP & $\begin{array}{l}\text { Effect } \\
\text { Allele }\end{array}$ & $\begin{array}{l}\text { Other } \\
\text { Allele }\end{array}$ & $\begin{array}{l}\text { Effect allele } \\
\text { frequency }\end{array}$ & Beta & Standard error & P value & $\mathbf{R}^{2}$ & $\mathbf{F}$ \\
\hline rs73026617 & $\mathrm{T}$ & $\mathrm{C}$ & 0.097 & 0.0474 & 0.0068 & $3.16 \mathrm{E}-12$ & $3.58 \mathrm{E}-04$ & 73.16 \\
\hline rs12083537 & A & $\mathrm{G}$ & 0.193 & 0.0643 & 0.0053 & $7.14 \mathrm{E}-34$ & 1.17E-03 & 239.60 \\
\hline rs4556348 & $\mathrm{T}$ & $\mathrm{C}$ & 0.148 & 0.0541 & 0.0067 & $6.77 \mathrm{E}-16$ & $6.71 \mathrm{E}-04$ & 137.25 \\
\hline rs2228145 & A & $\mathrm{C}$ & 0.36 & 0.0899 & 0.0042 & $1.21 \mathrm{E}-101$ & 3.39E-03 & 694.37 \\
\hline rs11264224 & A & $\mathrm{C}$ & 0.193 & 0.0465 & 0.0057 & $3.41 \mathrm{E}-16$ & $6.12 \mathrm{E}-04$ & 125.23 \\
\hline rs12059682 & $\mathrm{T}$ & $\mathrm{C}$ & 0.196 & -0.0441 & 0.0049 & $2.26 \mathrm{E}-19$ & $5.57 \mathrm{E}-04$ & 113.96 \\
\hline rs34693607 & C & $\mathrm{G}$ & 0.184 & 0.0368 & 0.0057 & $1.07 \mathrm{E}-10$ & $3.70 \mathrm{E}-04$ & 75.59 \\
\hline
\end{tabular}

Table showing the summary data for the variants that proxy IL-6 signalling inhibition. SNP: single nucleotide polymorphism. Beta is the unit change in natural $\log$ transformed CRP $(\mathrm{mg} / \mathrm{L})$ per copy increment in the effect allele. $\mathrm{R}^{2}$ represents the variance in CRP explained by the respective genetic variant. F-statistic measures the strength of the instrumental variable with the exposure. Variants identified and associated well with IL-6 signalling inhibition in a previous Mendelian randomization study exploring IL-6 inhibition and effects on ischaemic stroke and cardiovascular outcomes. ${ }^{16}$ 
Appendix 5: Estimates for the association of genetically proxied inhibition of IL-6 signalling with measures of renal function in sensitivity analysis.

Chronic Kidney Disease: association of genetically proxied IL-6 inhibition on Chronic Kidn ey Disease

\begin{tabular}{|l|l|l|l|}
\hline Method & Estimate (standard error) & $\begin{array}{l}\text { Odds ratio } \\
\mathbf{9 5 \%} \text { Confidence Interval) }\end{array}$ & P value \\
\hline Inverse-variance weighted & $-0.018(0.052)$ & $0.982(0.887-1.087)$ & 0.723 \\
\hline Simple median & $-0.009(0.111)$ & $0.991(0.797-1.232)$ & 0.936 \\
\hline Weighted median & $-0.006(0.088)$ & $0.994(0.837-1.181)$ & 0.943 \\
\hline MR-Egger & $0.105(0.239)$ & $1.11(0.695-1.774)$ & 0.678 \\
\hline MR-Egger intercept & $-0.008(0.011)$ & $0.992(0.971-1.013)$ & 0.490 \\
\hline
\end{tabular}

\section{Cochran's Q statistic:}

- Inverse-variance weighted analysis: 2.96 (SNPs 6), $p=0.814$

Log estimated glomerular filtration rate: association of genetically proxied inhibition of IL-6 signalling with log odds of estimated glomerular filtration rate

\begin{tabular}{|l|l|l|l|}
\hline Method & Estimate (standard error) & 95\% confidence interval & P value \\
\hline Inverse-variance weighted & $0.001(0.004)$ & $-0.007-0.009$ & 0.862 \\
\hline Simple median & $-0.004(0.005)$ & $-0.014-0.006$ & 0.376 \\
\hline Weighted median & $-0.001(0.003)$ & $-0.007-0.005$ & 0.688 \\
\hline MR-Egger & $-0.006(0.013)$ & $-0.031-0.019$ & 0.687 \\
\hline MR-Egger intercept & $0.0004(0.0008)$ & $-0.002-0.001$ & 0.636 \\
\hline
\end{tabular}

Cochran's Q statistic:

- Inverse-variance weighted analysis: 11.98 (SNPs 5), $\mathrm{p}=0.062$

Blood urea nitrogen: association of genetically proxied IL-6 inhibition on blood urea nitrogen

\begin{tabular}{|l|l|l|l|}
\hline Method & Estimate (standard error) & 95\% confidence interval & P value \\
\hline Inverse-variance weighted & $0.008(0.007)$ & $-0.006-0.022$ & 0.218 \\
\hline Simple median & $0.003(0.010)$ & $-0.017-0.023$ & 0.759 \\
\hline Weighted median & $0.008(0.009)$ & $-0.01-0.026$ & 0.350 \\
\hline MR-Egger & $0.029(0.023)$ & $-0.016-0.074$ & 0.260 \\
\hline
\end{tabular}

This article is protected by copyright. All rights reserved. 


\section{Cochran's Q statistic:}

- Inverse-variance weighted analysis: 5.30 (SNPs 5), $p=0.505$
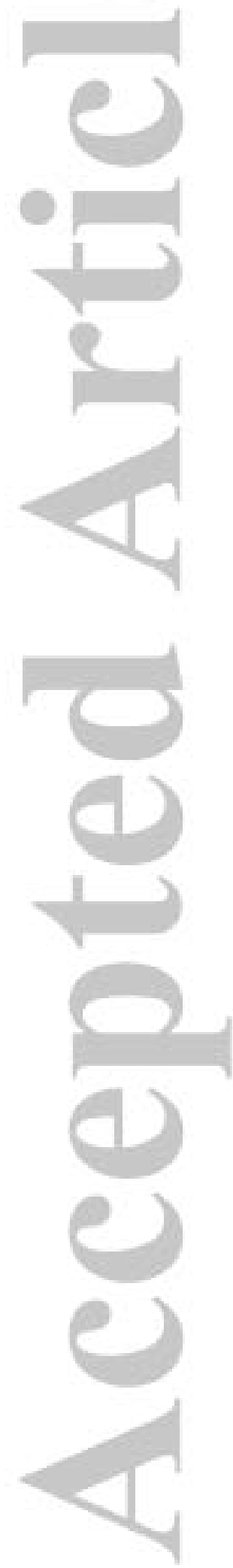


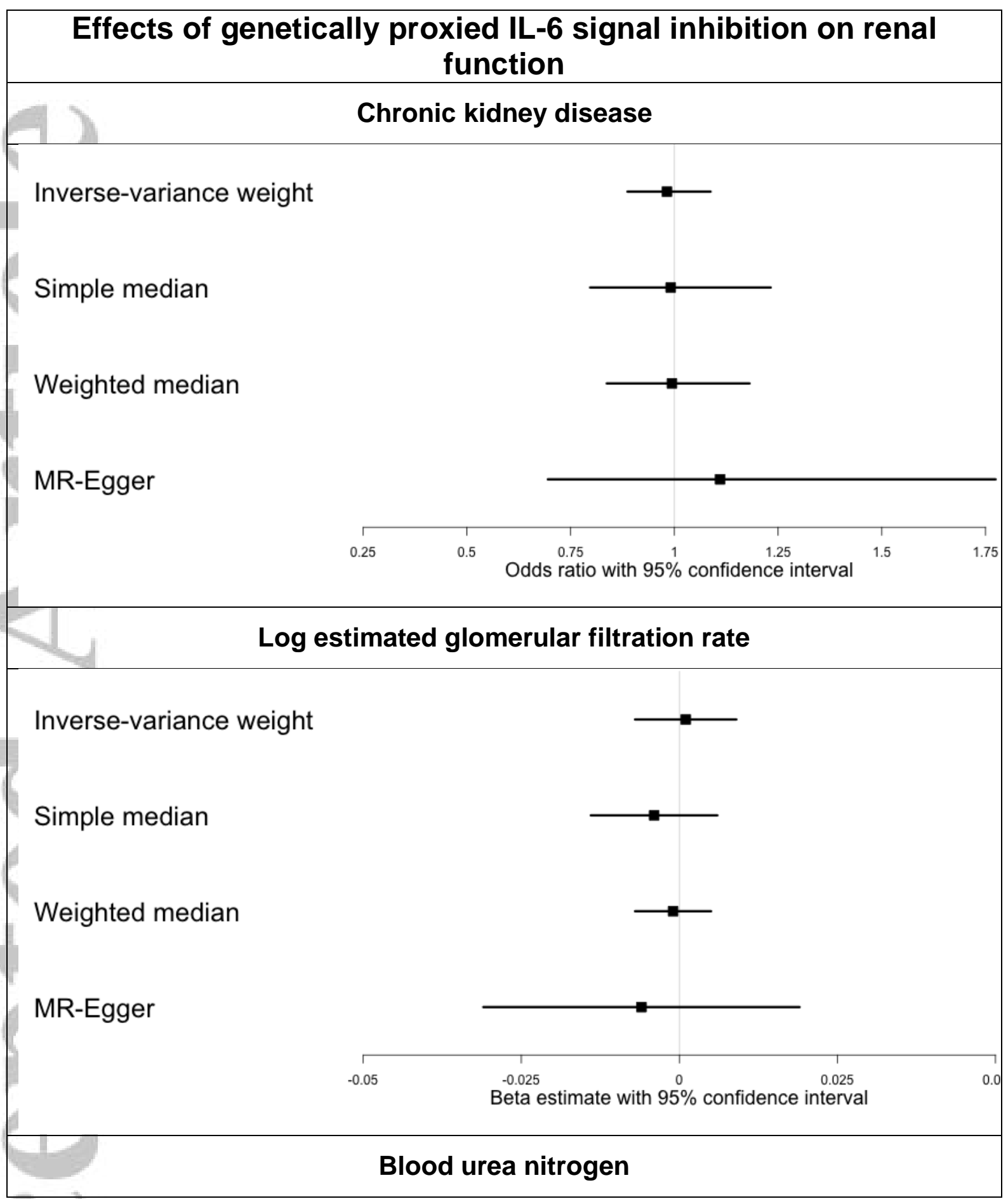




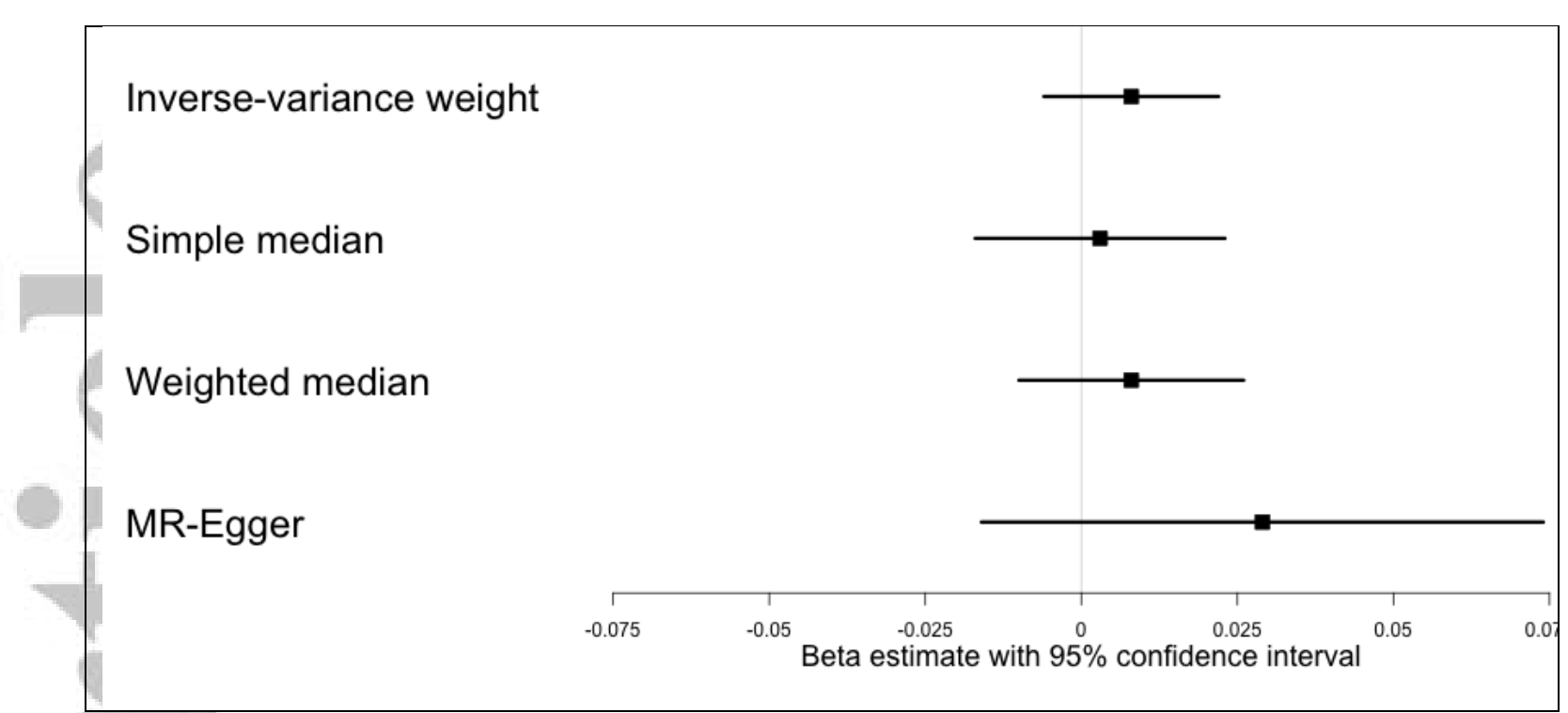

Sensitivity Analysis: Variants from the CHARGE consortium

Forest plots showing the Mendelian randomization estimates for chronic kidney disease (CKD), log eGFR (estimated glomerular filtration rate) and blood urea nitrogen (BUN) with different analysis methods (simple median, weighted median, inverse-variance weighted, MR-Egger). eGFR and BUN are presented as causal estimates with 95\% confidence interval. $\mathrm{CKD}$ is described as the odds ratio (95\% confidence interval) of having CKD with genetically proxied IL-6 signalling inhibition. 